\title{
2 - Habituating primates: processes, techniques, variables and ethics
}

\author{
ELIZABETH A. WILLIAMSON' AND ANNA T. C. FEISTNER ${ }^{2}$ \\ 'Scottish Primate Research Group, Department of Psychology, University \\ of Stirling, Stirling, UK \\ ${ }^{2}$ Durrell Wildlife Conservation Trust, Trinity, Jersey, Channel Islands
}

\section{INTRODUCTION}

Field biologists adopted the term habituation from physiology, as the relatively persistent waning of a response as a result of repeated stimulation that is not followed by any kind of reinforcement (Thorpe, 1963). Repeated neutral contacts between non-human primates (hereafter called primates in this chapter) and humans can lead to a reduction in fear, and ultimately to the ignoring of an observer. The techniques and processes involved have only rarely been described (e.g. Schaller, 1963; Kummer, 1995), as habituation has generally been viewed as a means to an end (Tutin \& Fernandez, 1991). The few studies that have quantified primate behaviour in relation to habituators describe the process with African great apes (Grieser Johns, 1996; van Krunkelsven et al., 1999; Blom et al., 2001). As we become increasingly aware of the potential effects of observer presence on primate behaviour, and especially the potential risks of close proximity with humans, it behoves us to measure as much as possible about the habituation process.

Many behavioural responses are taxon specific, and these should be taken into account when one is trying to habituate human-naïve wild primates. Between us we have had experience with a wide range of wild primates, ranging in size from marmosets (Callithrix spp.) to gorillas (Gorilla spp.), from South America, Africa, Madagascar and Asia, which, together with discussions with colleagues, we have used to make this chapter as broadly applicable as possible. Our emphasis is on what to take into account when considering primate habituation, particularly in relation to preparation, observer behaviour, and assessing the risks that habituation to humans may pose for increasingly endangered primates. Since habituating African great apes probably presents the greatest challenge, the aspects that we illustrate with reference to apes will in most cases be applicable to designing an approach with other primates.

There are limits to what studies of unhabituated primates can achieve: it is difficult to observe at close range, so subtle or cryptic behaviour such as facial expressions and soft vocalisations may be missed, and even individual 
identification may be difficult, resulting in analyses based only on age-sex classes. Primates disturbed by the presence of observers will show altered patterns of behaviour and it may not be possible to follow groups on the move. Habituation allows an observer to approach closely, because subjects no longer flee and do not seem to respond to observers, allowing us to become familiar with individuals, and fine-level behaviours such as subtle social interactions or food processing can be observed. When the researcher is following habituated animals, behaviour can be sampled consistently.

\section{METHODS \\ PREPARATION}

\section{Knowing your primate}

To prepare for a study involving primate habituation, first read as much about your target species and its environment as possible. Familiarise yourself with what others have done and with your species' basic behavioural repertoire. Secondly, try to gain exposure to the species itself, perhaps by visiting a zoo to observe the animal directly. The more naturalistic the physical and social environment of the captive primate, the better its potential as a model for wild conspecifics. Spending time observing captive primates will increase familiarity with their basic locomotor patterns and postures, facial expressions, and other behaviours, including foraging and food processing, grooming, play, reproductive and agonistic interactions. Pay particular attention to vocalisations, since these may be a means of locating wild primates and will help you to interpret behaviour in the absence of clear observation. Concentrate on alarm and display behaviours, as these are likely to be initial responses to human presence. Observing captive primates will also provide an opportunity to learn how to distinguish individuals and will give you a head start in recognising primates in the wild.

\section{Equipment}

In the early stages, little equipment is needed: binoculars, a notebook, a compass, maps and a Global Positioning System (Chapter 4). Binoculars and cameras should be used with care; pointing a big 'eye' towards primates can make them uneasy.

\section{Using a trail system}

Trails can facilitate movement within the study area and make it easier to follow primate groups, but this depends greatly on vegetation type and even more on the area to be covered, which is likely to be determined by home range size. For example, in Taï, Côte d'Ivoire, researchers studying chimpanzees (Pan troglodytes verus) worked alone, and did not cut transects or trails but learnt to orient themselves in the forest with a compass. We took the same approach with lowland gorillas (Gorilla gorilla gorilla) at Lopé, Gabon, 
where an additional factor was fast growing Marantaceae vines that would have required labour-intensive trail maintenance. Learning the lie of the forest, using features such as streams and vegetation types, without trail cutting keeps disturbance to a minimum. In African forests with high elephant density, it is also possible to use established networks of elephant trails.

Some researchers studying monkeys with home ranges that are smaller than those of apes have found a trail system to be invaluable. Kaplin judged that establishing a trail system was crucial in keeping up with blue monkeys (Cercopithecus mitis) and therefore to habituating them, and that 'building it as we went was key. It was created to facilitate animal follows, and improved as we came to know the animals and began to predict where we could find them. The trail system allowed us to move more quickly through the forest, and to open access to places where the monkeys had travelled previously' (B.A. Kaplin, personal communication, 2002). Other researchers have established trails on a grid system prior to, or during, the early part of studies (e.g. at Bezamahafaly, Madagascar) or have worked in areas that have previously been logged, so an old trail or grid system may exist (e.g. at Lopé and at Kirindy, Madagascar).

\section{FINDING YOUR PRIMATE}

Frequent contacts with the same individuals are necessary to achieve habituation, so a daily objective is usually to locate a known group or individual. Some researchers have trapped and radio-tagged primates as an aid in locating them. This option has to be considered carefully for several reasons, including ethical ones. In addition, depending on the species and procedures used, catching and marking may actually set back the habituation process (Sterling, 1993; Chapters 7 and 10). Assuming that catching and marking is not used, primates need to be located by other means. Searching at random in the hope of encountering your primate is unlikely to be a successful strategy, especially when the animals are in small and cryptic groups or occur at low densities (e.g. lowland gorillas usually occur at about one group per $10 \mathrm{~km}^{2}$ ). It is extremely helpful to have prior knowledge about the behavioural ecology of your species, but when this is not possible, some practical decisions and a number of clues may help in locating primates and ensuring regular contact.

\section{Auditory clues}

Often the first indication of primate presence will be an auditory clue: vocalisations such as long-calls (e.g. chimpanzees, Pan troglodytes; gibbons, Hylobates spp.; howler monkeys, Alouatta spp.; arboreal guenons, Cercopithecus spp.; ruffed lemurs, Varecia variegata; indri, Indri indri), alarm calls or warning barks. Taking a compass bearing and heading in that direction may facilitate your approach. Alternatively, the sound of movement in the vegetation as 
animals travel may alert you to their presence. Groups of arboreal guenons and colobines may be quite noisy as branches and leaves move with their passage; species such as colobus and sifaka (Propithecus verreauxi) make a thump as they land on larger branches and trunks; or you may hear the sound of food processing or plant parts dropping to the ground. Indirect clues to the previous presence of primates in the area include ape nests and a variety of feeding signs.

\section{Waiting at key sites}

An alternative to searching for your study primates is to wait for them to come to you by identifying key sites where it may be possible to encounter them regularly. Being at an animal's sleeping site before it wakes up and leaves means that you can locate your animal early in the day and become part of the surroundings the animal sees on waking up. Most primates sleep above ground, so aim to be close to nests, sleeping-cliffs, sleeping-trees or close to tree holes before dawn (before dusk for nocturnal primates). Predictable food resources such as figs, salt licks, water sources and seasonally available foods with limited distribution are also good places to locate primates.

It is possible to establish key sites through provisioning, which is the use of artificial feeding as a positive incentive to tolerate human presence, first used 50 years ago in the habituation of Japanese snow monkeys (Macaca fuscata) at Koshima, Japan (Watanabe, 2001). If food is provided at limited sites, as at the feeding station for chimpanzees at Gombe in Tanzania, then the animals will be attracted to that site. It may be easier to observe and habituate them there, rather than to try to locate them in the forest. They can then gradually be followed as they leave the site. However, provisioning carries with it the disadvantage of modifying natural behaviour patterns. At Gombe and Mahale, Tanzania, changes in chimpanzee activity budgets, aggression, and territoriality were recorded (Wrangham, 1974; Power, 1986). Provisioning also requires considerable resource, otherwise only a few individuals may become habituated. For example, the dominant 'alpha' males monopolise bananas at Gombe unless a large quantity is supplied (D. A. Collins, personal communication, 2002). Moreover, provisioning can affect non-target species: at Gombe baboons (Papio cynocephalus) were habituated as a side effect of the provisioning for chimpanzees (D. A. Collins, personal communication, 2002).

\section{APPROACHING YOUR ANIMALS}

How contact is established is one of most important elements of successful habituation, and various factors should be taken into account. Above all, avoid surprise; sudden contacts that frighten the animals will always be a negative experience. Boesch-Achermann \& Boesch's (1994) basic method was 'being seen by the chimpanzees as often as possible and always in a peaceful, discreet attitude'. Thus it is desirable to be clearly visible to the primates, initially at 
a distance greater than that which invokes alarm and flight. Obviously the practicalities of this will depend on habitat variables (discussed below).

Habituation can be achieved only when the primate sees you, but try to choose the moment. Once you make your presence known, the animals are likely to leave, so it will be necessary to sacrifice observations in order to achieve progress. Many primates rapidly identify human faces, therefore the same observers should contact the animals, at least during the initial stages of habituation. It is also helpful to be consistent in your appearance (wear the same clothing, hat, rucksack, etc.). Habituators should behave calmly and attempt to 'reassure' animals by remaining still and/or mimicking natural behaviours, such as grooming or feeding. A crouching position is less intimidating and bonobos (Pan paniscus), for example, responded more positively when an observer was sitting rather than walking (van Krunkelsven et al., 1999).

\section{Signalling your presence}

With apes it is often useful to adopt a signal that communicates your presence and which they learn to associate with your approach. This signal should be a specific noise, which becomes identified with a non-threatening neutral presence. 'Belch' or 'tongue-clacking' vocalisations are used with gorillas.

\section{Keeping your distance}

Generalisations are difficult to make, but you should err on the side of caution, while trying to maintain good visibility between primate and observer. Appropriate distances will depend on the environment, especially vegetation density, visibility, and species concerned.

\section{What not to do}

Certain behaviours should be avoided, such as making loud noises, sudden gestures, or surreptitious movements, although tolerance will depend on species and habitat. Most primates do not like to be followed (which may resemble predator tracking), but seem to respond better to arriving upon an observer. Moreover 'pushing' primates ahead of you by following them may cause them to incur unnecessary energetic costs. Primates do not like to be crept up on, so avoid hiding and help them to keep track of your location by vocalising. Avoid pointing with telephoto lenses, sticks or guns.

Primates are also sensitive to the number of people present, so it is better to habituate with only one or two observers, preferably the same people. Even habituated primates may alter their behaviour with increased numbers of observers; for example, stumptail macaques (Macaca arctoides) reacted differently to a team of observers than to the presence of one or two (Rasmussen, 1991) and Sulawesi crested black macaques (Macaca nigra) were more likely to flee or climb trees when visited by larger groups of people (Kinnaird \& O’Brien, 1996). Mongoose lemurs (Eulemur mongoz) exhibited signs of agitation 
Table 2.1. Typical reactions of primates to observer presence during the habituation process

\begin{tabular}{ll}
\hline Behaviour & Definition \\
\hline Flight & $\begin{array}{l}\text { Rapid, often noisy, panicked departure coupled with alarm or fear } \\
\text { vocalisations, but no display }\end{array}$ \\
Avoidance & $\begin{array}{l}\text { Groups are relatively calm, silent and disappear quickly without } \\
\text { displaying; they 'melt' into the forest }\end{array}$ \\
Curiosity & $\begin{array}{l}\text { Responses range from brief monitoring (surveillance), to moving to } \\
\text { acquire a clearer view of an observer, to approaching the observer }\end{array}$ \\
Display & $\begin{array}{l}\text { Vocalisations and species-typical displays (e.g. chest-beats, branch } \\
\text { bouncing, yawns) are directed at the observer }\end{array}$ \\
Ignore &
\end{tabular}

if unknown observers were present or more than one to two people followed them (D. J. Curtis, personal communication, 2002).

\section{DATA RECORDING}

Systematic records are useful for assessing progress towards habituation, so we recommend recording the following: (1) time at which search started, (2) time at which animals were located, (3) how animals were located, (4) observer-primate distance (often useful to measure perpendicular distance and height, e.g. guenons at $40 \mathrm{~m}$ and at 15-20 m height), (5) activity of animals when contacted, (6) animal's behaviour in response to observer, (7) time at end of contact, and (8) how contact ended. As a minimum, both cumulative contact time (after your presence has been detected), observation time and location of subjects can be readily collected at all field sites.

Habituation can occur only when the same individuals are contacted on a regular basis, so it will be important to know whether you are seeing the same individuals. In addition to sex and age class, try to record also shape of face, ears and nose pattern (for apes), pelage pattern (e.g. some lemurs) and any scars, notches in ears, missing fingers or toes, broken canines, bent/broken tails.

Changes in behaviour during habituation are rarely monitored, but provide valuable information for quantifying the process and measuring the changing impact of observer presence. Choose simple categories of behaviour that can be quantified (Table 2.1).

\section{KNOWING WHEN YOUR PRIMATE IS HABITUATED}

Ideally your subjects will be aware of your presence yet learn to ignore you. Over the course of habituation both primate and observer behaviour is likely 
to change. As familiarity with the study species and its habitat increases, your ability to move around the study area, pick up clues to primate location and identify individuals should improve, reducing search time. Moreover, as the primates become habituated to your presence, there should be an increase in the duration of average contact time, and decreases in flight, avoidance and display behaviours. Work with both lowland gorillas and Geoffroy's tamarins (Saguinus geoffroyi) has shown that day ranges decreased with habituation (Rasmussen, 1998; Blom et al., 2001). The ratio of habituation time to observation time should change, but be patient and do not have high expectations: mean contact time with lowland gorillas increased from about 7 minutes to only 20 minutes over three years (Blom et al., 2001). Consistency of observers, or possible 'hand-over' periods may be helpful if different people are likely to be involved in habituation, although this should be avoided during the early phases. Rasmussen (1991) reported that observers who were at ease, and not intimidated (by stumptail macaques), evoked a different response than neophyte observers. It is worth sounding a note of caution here: can we ever assume that a study animal behaves as it would if no observer were present? Rasmussen (1991) found that habituated stumptail macaques still adjusted their travel in the presence of observers after almost daily contact for 14 years.

Habituation is an ongoing process, especially as group composition can change during the study period owing to immigration, emigration, births and deaths. The time taken to habituate depends on a large range of factors, which may be taxon specific, habitat based, or linked to the primates' previous experience of humans. A rough guide to habituation time is presented in Table 2.2.

Most nocturnal primates (bushbabies, Galago spp.; sportive lemurs, Lepilemur spp.; woolly lemurs Avahi spp.; and dwarf lemurs, Cheirogaleus spp.; but not aye-ayes) do not appear to need habituating at all, they simply continue their activity after noticing the presence of an observer. Diurnal and cathemeral lemurs that have not been hunted and are accustomed to humans passing through the forest can be habituated in a matter of a few days to less than a month (Andrews \& Birkinshaw, 1998; Curtis, 1998). Human-naïve lemurs approach observers and may even touch them (these lemurs need habituating to the point of ignoring rather than approaching the observer). It took about three months to be able to follow arboreal mangabeys (Cercocebus albigena) without disturbing them or causing them to flee, but six months before there was no noticeable effect of observer presence on their behaviour (R. Kormos, personal communication, 2002). Similarly, it took three months before a group of patas monkeys (Erythrocebus patas) could be followed all day, and six months before animals could be reliably observed from $50 \mathrm{~m}$ (Chism \& Rowell, 1988). Hamadryas baboons (Papio hamadryas) could be approached to $60 \mathrm{~m}$ during daily marches within a year, but to be able to walk among them took about two years (Kummer, 1995). Only after a year of repeated contacts did lowland gorillas' reactions change from 
Table 2.2. Approximate times to habituate non-provisioned primates that have not been hunted

\begin{tabular}{|c|c|c|}
\hline Time frame & Primate taxa & Source \\
\hline$<1$ hour- $<1$ week & $\begin{array}{l}\text { Bushbabies (Galago spp.), } \\
\text { most nocturnal lemurs }\end{array}$ & $\begin{array}{l}\text { S. Bearder, A. Mueller, U. } \\
\text { Thalmann, personal } \\
\text { communication, } 2002\end{array}$ \\
\hline$\sim 1$ month & $\begin{array}{l}\text { Most diurnal and } \\
\text { cathemeral lemurs, } \\
\text { orangutans (Pongo } \\
\text { pygmaeus) }\end{array}$ & $\begin{array}{l}\text { A. T.C. Feistner, personal } \\
\text { observation; Rodman, } 1979\end{array}$ \\
\hline 2-5 months & $\begin{array}{l}\text { Aye-aye (Daubentonia } \\
\text { madagascariensis), pottos } \\
\text { (Perodicticus potto), } \\
\text { marmosets, tamarins, } \\
\text { savannah baboons } \\
\text { (Papio spp., except } \\
\text { hamadryas) }\end{array}$ & $\begin{array}{l}\text { Rylands, 1986; Barton \& } \\
\text { Whiten, 1993; Sterling, } \\
\text { 1993; Cowlishaw, 1997; } \\
\text { Passamani, 1998; } \\
\text { Rasmussen, 1998; E. Pimley, } \\
\text { personal communication, } \\
\text { 2002; Y. Warren, personal } \\
\text { communication, } 2002\end{array}$ \\
\hline 3-8 months & $\begin{array}{l}\text { Colobus (Colobus satanus), } \\
\text { guenons (Cercopithecus } \\
\text { l'hoesti, C. mitis), } \\
\text { mangabeys (Cercocebus } \\
\text { albigena), muriqui } \\
\text { (Brachyteles arachnoids) }\end{array}$ & $\begin{array}{l}\text { Strier, 1999; R. Ham, B.A. } \\
\text { Kaplin, M.J. S. Harrison, } \\
\text { personal communication, } \\
2002\end{array}$ \\
\hline $6+$ months & $\begin{array}{l}\text { Patas (Erythrocebus patas), } \\
\text { siamang (Hylobates } \\
\text { syndactylus) }\end{array}$ & $\begin{array}{l}\text { Chivers, 1974; Chism \& } \\
\quad \text { Rowell, } 1988\end{array}$ \\
\hline $1-2$ years & $\begin{array}{l}\text { Hamadryas baboons } \\
\text { (Papio hamadryas), } \\
\text { mountain gorilla } \\
\text { (Gorilla beringei beringei) }\end{array}$ & $\begin{array}{c}\text { Schaller, 1963; Kummer, } \\
\text { 1995; Butynski, } 2001\end{array}$ \\
\hline $2-5$ years & $\begin{array}{l}\text { Bonobo (Pan paniscus), } \\
\text { chimpanzee (Pan } \\
\text { troglodytes), lowland } \\
\text { gorilla (Gorilla gorilla } \\
\text { gorilla) }\end{array}$ & $\begin{array}{l}\text { Boesch-Achermann \& Boesch, } \\
\text { 1994; Susman, 1984; Blom } \\
\text { et al., } 2001\end{array}$ \\
\hline
\end{tabular}

aggression to ignore (Blom et al., 2001), yet titi monkeys (Callicebus personatus personatus) were habituated without systematic effort in about 12 weeks while following marmosets (Callithrix geoffroyi) (E. Price, personal communication, 2002). 


\section{FACTORS AFFECTING PRIMATE HABITUATION}

Many factors influence the success of habituation: some can be determined by the observer, such as contact distances and observer behaviour, while there are others which you cannot control, such as species-specific reactions, habitat variables and previous experience with humans, especially hunting. Many of these factors interact, but here we attempt to evaluate some of them.

\section{SPECIES-SPECIFIC FACTORS}

\section{Species differences}

In general, species that are opportunistic, such as macaques (Macaca spp.) and baboons (Papio spp.), are relatively easy to habituate because they are extrovert and adapt readily to changing circumstances. Unhabituated individuals may even approach observers with minor mobbing, eyebrow threats or lip smacking. Primates that live in stable groups also tend to be easier because when you encounter one individual you have usually found the whole group. Moreover, if one macaque or baboon approaches with no negative consequences, others may learn from watching that 'non' interaction. These species also tend to be much more interested in exploring novel foods and so respond quickly to provisioning. In contrast, more conservative chimpanzees travel in small groups and their fission-fusion society means that, if you follow two or three one day, you may encounter a different subgroup next day (D. A. Collins, personal communication, 2002).

Diet is an important factor. Arboreal folivores such as colobus tend to be easier to habituate than arboreal frugivores such as guenons. This is likely to be due to the former having smaller home ranges, and their food being available in larger patches so that more individuals can feed together and increased time is spent resting.

Home range size is also important: primates with large home ranges are more difficult to encounter consistently, partially explaining differences between mountain and lowland gorilla habituation, and perhaps the difficulties of habituating mandrills (Mandrillus sphinx) and drills (Mandrillus leucophaeus).

Even when sympatric, species can vary in their ease of habituation. For example, white-throated capuchins (Cebus capuchinus) have habituated to people, whereas squirrel monkeys (Saimiri oerstedi) in the same area of Costa Rica have not (Boinski \& Sirot, 1997). In addition, monkeys that sometimes occur in polyspecific groups may react differently depending on the circumstances. Kormos reports 'habituated mangabeys would flee without even looking if they were with unhabituated guenons who alarm called. On the other hand, they were much bolder in a polyspecific group' (R. Kormos, personal communication, 2002).

Finally, evolutionary history can influence ease of habituation. It may be that Madagascan prosimians are remarkably easy to habituate as a result 
of the reduced predator assemblage in Madagascar, combined with the very recent arrival of humans, only some 2000 years ago.

\section{Sex and age differences}

Responses differ according to age and sex of an individual primate. In multimale multi-female or harem groups, adult males tend to be larger, more aggressive and play patrolling or sentinel roles in groups. Thus they are more overt and often more exposed to observer contact than are females, which may well be carrying or protecting young. Male baboons, macaques, chimpanzees and gorillas respond to observers with displays and curiosity, while juveniles generally respond with more curiosity than do adults.

\section{HABITAT FACTORS: VISIBILITY}

A clear view of the observer is one of the most important factors in habituation. Primates (such as baboons) living in more open habitats tend to be easier to habituate than those (such as mandrills) living in dense forest, both within and between taxa. In open habitats, such as savannah areas, primates can see you from a distance and you can gradually move closer. However, open habitats may still have poor visibility and patas monkeys, for example, are notoriously difficult to habituate (Chism \& Rowell, 1988).

In the Virunga volcanoes, low vegetation and uneven topography provided ideal conditions where mountain gorillas (Gorilla beringei beringei) could be watched from the opposite side of a ravine. In contrast, visibility in lowland forest is poor, and lowland gorillas are usually obscured even within $10 \mathrm{~m}$ of an observer, unless they climb trees (Williamson, 1988). Sudden contacts are difficult to avoid in dense forest, and probably hinder habituation by frightening the animals.

Issues of visibility could explain differences between terrestrial and arboreal forest primates. Arboreal guenons are generally easier to habituate than terrestrial ones. For example, terrestrial l'Hoest's guenons (Cercopithecus l'hoesti) are more wary when followed on the ground; they flee and become completely still. In contrast, arboreal blue monkeys are apparently less concerned by observer presence when high in the trees (B.A. Kaplin, personal communication, 2002). Semi-terrestrial pigtail macaques (Macaca nemestrina) are more difficult to habituate than arboreal long-tailed macaques (Macaca fascicularis). Terrestrial sun-tailed guenons (Cercopithecus solatus) seem almost impossible to habituate owing to their large home ranges and cryptic habits.

\section{ETHICAL ISSUES}

One should seriously evaluate whether or not to attempt habituation if doing so may have a significant long-term effect on normal activity and behaviour patterns, and in particular if habituation may increase disease risks by changing the nature of contact between humans and non-human primates. 


\section{RISKS TO OBSERVERS}

\section{Risks during habituation}

During the habituation process, aggression initially increases, peaks and then diminishes to low levels (Blom et al., 2001); thus, in the early stages, a habituator may be subject to intimidating displays. These are more likely to be unpleasant than dangerous; however, people have received canine puncture wounds during mountain gorilla habituation.

\section{Risks as a result of habituation (overhabituation)}

A primary aim of habituation is for the observer to be a neutral element in the habitat. However, primates such as chimpanzees, baboons and macaques are highly intelligent, complex, socially manipulative animals, and overfamiliarity with the observer may change the observer from being a 'piece of the furniture' to a social tool, available for inclusion in their social relations. Being 'used' by your study animals is rarely mentioned in the literature, although it probably happens regularly (A.T.C. Feistner \& E.A. Williamson, unpublished data). Well-habituated mountain gorillas sometimes redirect aggression towards a more vulnerable observer rather than a conspecific, and baboons and macaques may use observers in a display or to avoid aggression from others. Even seemingly harmless interactions such as a juvenile playing with a shoelace can quickly lead to incite-screaming, leaving the observer in trouble.

Loss of fear of humans can lead to negative interactions with local people: baboons at Gombe attack and steal from villagers (D. A. Collins, personal communication, 2002); habituated mountain gorillas in Uganda feed in fields outside a national park and have attacked people in fields (Butynski, 2001). Loss of fear through over-habituation and/or poorly managed contacts poses severe problems for local human populations, ecotourism programmes and primate conservation.

\section{RISKS TO PRIMATES}

\section{Disease transmission between humans and non-human primates}

Close proximity with researchers is likely to increase risks of disease transmission (Chapters 1 and 8). Illnesses to which animals have never been exposed are potentially the most dangerous. Homsy (1999) reviewed epidemiological data and disease transmission between people and apes. Studies of captive apes show that they have a definite susceptibility to human diseases, but not the same resistance as humans. As a result of this shared susceptibility, certain human pathogens, both respiratory (measles, herpes, pneumonia) and enteric diseases (polio, salmonella), can affect apes, and deaths are known to have occurred in wild populations (Butynski, 2001). Risks are greatest to terrestrial primates, which tend to come into closer proximity to people. Quarantine for researchers and minimum distance rules, such as those implemented at 
Karisoke Research Centre, Rwanda, should be in place for all populations of primates. A suite of common-sense observer behaviours can reduce the risks: avoiding physical contact, maintaining minimum distances, careful management of waste products, avoiding excretion in the forest and not working if feeling unwell.

\section{Stress}

Stress provoked during the habituation process could potentially reduce reproductive success or result in immunosuppression and increase susceptibility to disease (Woodford et al., 2002).

\section{Generalisation to other humans}

Since habituation is basically the loss of fear of humans, we may make animals easily approachable by hunters and poachers, and render them extremely vulnerable in dangerous situations. Thus the future of a study population and the ability to sustain protection should be contemplated carefully before the researcher decides to habituate.

\section{OTHER IMPACTS ON PRIMATE BEHAVIOUR}

The presence of an observer can have a direct effect on the activity of habituated primates, and several indirect effects by changing the target species' interactions with its conspecifics, predators, prey, and other species in its environment.

\section{Protection from natural predators}

Carnivores such as hyena (Hyaena hyaena), lions (Panthera leo), leopards (Panthera pardus), ocelots (Leopardas pardalis), and fossa (Cryptoprocta ferox) are unlikely to approach when a human observer is present, so habituated groups may inadvertently be protected from predation.

\section{Behaviour with conspecifics}

Regular contact with humans may cause changes in primate behaviour such as hindering reproduction, altering inter-group dynamics and impeding transfer between groups. Habituated and unhabituated primates respond differently to people, so a human presence may well alter the nature of interactions between neighbouring groups. The presence of an observer thus unintentionally benefits a habituated group, for example a naïve group may flee, enabling the study group to take over a favoured food resource (Rasmussen, 1991).

\section{Impacts on activity}

Observer presence can have negative impacts on behaviour: study groups have larger day ranges if they try to flee or avoid human contact during the initial 
stages of habituation. They also expend more energy. Activity budgets may change, as feeding and other activities will be disrupted while the animals move away from habituators. In some cases primates appear to alter their activity in the presence of an observer, for example chimpanzees 'sit down and wait for us to catch up if we're slow and also disappear into deep thickets to lose us' (J. Setchell, personal communication, 2001).

\section{CONCLUSIONS}

In this chapter we have tried to explore the factors that affect habituation of primates to human observers. The key to success is persistent, regular and frequent neutral contact with the same individuals. In most cases habituation requires considerable time investment - from months to years, depending on species and environment (with Madagascan prosimians the exception). We suggest that anyone considering habituating primates for research purposes should: (1) think carefully about the pros and cons, especially the potential risks; (2) familiarise themselves with their study species prior to going to the field; (3) engage and use their common sense; and (4) record, measure and evaluate the habituation process. Habituation is usually hard work but the rewards, both personal and academic, are great: being in the company of wild primates who have accepted you into their environment and allow you an insight into their daily lives is a privilege.

\section{ACKNOWLEDGEMENTS}

We wish to thank James R. Anderson, D. Anthony Collins, Rebecca Kormos, Michael J. S. Harrison, Beth A. Kaplin, Eluned C. Price Urs Thalmann and Ymke Warren for sharing their experiences during the preparation of this chapter.

\section{REFERENCES}

Andrews, J.R. \& Birkinshaw, C. R. (1998). A comparison between daytime and nighttime diet, activity and feeding height of the black lemur, Eulemur macaco (Primates: Lemuridae), in Lokobe Forest, Madagascar. Folia Primatol. 69, Suppl. 1, 175-82.

Barton, R.A. \& Whiten, A. (1993). Feeding competition among female olive baboons, Papio anubis. Anim. Behav. 46, 777-89.

Blom, A., Cipolletta, C., Brunsting, A. R.H. \& Prins, H.H.T. (2001). Behavioural responses of gorillas to habituation in the Dzanga-Ndoki National Park, Central African Republic. In Ecological and economic impacts of gorilla-based tourism in Dzanga-Sangha, Central African Republic, A. Blom, pp. 91-124. Ph.D. thesis: University of Wageningen.

Boesch-Achermann, H. \& Boesch, C. (1994). The Tai Chimpanzee Project in Côte d'Ivoire, West Africa. Pan Africa News 1, 5-7. 
Boinski, S. \& Sirot, L. (1997). Uncertain conservation status of squirrel monkeys in Costa Rica, Saimiri oerstedi oerstedi and Saimiri oerstedi citrinellus. Folia Primatol. 68, 181-93.

Butynski, T. M. (2001). Africa's great apes. In Great Apes \& Humans: The Ethics of Coexistence, ed. B. B. Beck, T. S. Stoinski, M. Hutchins, T. L. Maple, B. Norton, A. Rowan, E. F. Stevens \& A. Arluke, pp. 3-56. Washington, DC: Smithsonian Institution Press.

Chism, J. \& Rowell, T.H. (1988). The natural history of patas monkeys. In A Primate Radiation: Evolutionary Biology of the African Guenons, ed. A. GautierHion, F. Bourlière, J.-P. Gautier \& J. Kingdon, pp. 412-38. Cambridge: Cambridge University Press.

Chivers, D.J. (1974). The Siamang in Malaya: a field study of a primate in tropical rain forest. Contrib. Primatol. 4, 1-335.

Cowlishaw, G. (1997). Trade-offs between foraging and predation risk determine habitat use in a desert baboon population. Anim. Behav. 53, 667-86.

Curtis, D.J. (1998). Group size, home range use, and seasonal variation in the ecology of Eulemur mongoz. Int. J. Primatol. 19, 811-35.

Grieser Johns, B. (1996). Responses of chimpanzees to habituation and tourism in the Kibale Forest, Uganda. Biol. Conserv. 78, 257-62.

Homsy, J. (1999). Ape Tourism and Human Diseases: How Close Should We Get? Report to the International Gorilla Conservation Program. Website: <www.wildlifeinformation.org/subdirectories_fer_search/sampleEL/ greatape.pdf $>$.

Kinnaird, M.F. \& O’Brien, T. G. (1996). Ecotourism in the Tangkoko DuaSudara Nature Reserve: Opening Pandora's box? Oryx 30, 65-73.

Kummer, H. (1995). In Quest of the Sacred Baboon. Princeton, NJ: Princeton University Press.

Passamani, M. (1998). Activity budget of Geoffroy's marmoset (Callithrix geoffroyi) in an Atlantic forest in southeastern Brazil. Am. J. Primatol. 46, 333-40.

Power, M. (1986). The foraging adaptation of chimpanzees, and the recent behaviors of the provisioned apes in Gombe and Mahale National Parks, Tanzania. J. Hum. Evol. 1, 251-65.

Rasmussen, D.R. (1991). Observer influence on range use of Macaca arctoides after 14 years of observation? Lab. Prim. Newsl. 30, 6-11.

(1998). Changes in range use of Geoffroy's tamarins (Saguinus geoffroyi) associated with habituation to observers. Folia Primatol. 69, 153-9.

Rodman, P.S. (1979). Individual activity patterns and the solitary nature of orangutans. In Perspectives On Human Evolution, vol. 5, The Great Apes, ed. D.A. Hamburg \& E.R. McCown, pp. 235-55, Menlo Park, CA: Benjamin/Cummings Publishing Co.

Rylands, A. B. (1986). Ranging behaviour and habitat preference of a wild marmoset group, Callithrix humeralifer (Callitrichidae, Primates). J. Zool. Lond. 210, 489-514. 
Schaller, G. B. (1963). The Mountain Gorilla: Ecology \& Behavior. Chicago: University of Chicago Press.

Sterling, E.J. (1993). Behavioral ecology of the aye-aye (Daubentonia madagascariensis) on Nosy Mangabe, Madagascar. Ph.D. thesis: University of Yale.

Strier, K. B. (1999). Faces in the Forest: The Endangered Muriqui Monkeys of Brazil. Cambridge, MA: Harvard University Press.

Susman, R.L. (1984). The locomotor behavior of Pan paniscus in the Lomako Forest. In The Pygmy Chimpanzee. Evolutionary Biology and Behavior, ed. R. L. Susman, pp. 369-93. New York: Plenum Press.

Thorpe, W.H. (1963). Learning and Instinct in Animals. London: Methuen.

Tutin, C.E.G. \& Fernandez, M. (1991). Responses of wild chimpanzees and gorillas to the arrival of primatologists: behaviour observed during habituation. In Primate Responses to Environmental Change, ed. H. O. Box, pp. 187-97. London: Chapman \& Hall.

van Krunkelsven, E., Dupain, J., van Elsacker, L. \& Verheyen, R. (1999). Habituation of bonobos (Pan paniscus): first reactions to the presence of observers and the evolution of response over time. Folia Primatol. 70, 365-8.

Watanabe, K. (2001). A review of 50 years of research on the Japanese monkeys of Koshima: status and dominance. In Primate Origins of Human Cognition And Behavior, ed. T. Matsuzawa, pp. 405-17. Tokyo: Springer-Verlag.

Williamson, E.A. (1988). Behavioural ecology of Western Lowland Gorillas in Gabon. Ph.D. thesis: University of Stirling.

Woodford, M., Butynski, T. M. \& Karesh, W. (2002). Habituating the great apes: the disease risks. Oryx 36, 153-60.

Wrangham, R.W. (1974). Artificial feeding of chimpanzees and baboons in their natural habit. Anim. Behav. 22, 83-93. 